\title{
EDITORIAL
}

\section{Nuevos organismos internacionales para una aldea global}

$\mathrm{L}$ a institucionalización de la cooperación internacional se produjo en el siglo XIX en respuesta a la diseminación transfronteriza de enfermedades transmisibles. A principios del siglo XX se fortaleció al ampliarse sus funciones para incluir, entre otras tareas, el diseño de estándares y normas, y el apoyo sanitario directo a países con menores niveles de desarrollo. Los avances tecnológicos de la primera mitad del siglo $X X$ permitieron extender todavía más las áreas de cooperación, lo que generó resultados espectaculares sobre todo en el campo de las enfermedades prevenibles por vacunación. La gran historia de éxito de la salud internacional del siglo pasado, inimaginable en ausencia de los organismos multilaterales de salud, fue la erradicación de la viruela. A este logro mundial habría que agregar, en el ámbito de las Américas, la eliminación regional de la poliomielitis y del sarampión autóctono.

Ahora, con la intensificación sin precedentes del comercio, el turismo y la migración, y con la revolución de las comunicaciones, parece necesario detenernos de nueva cuenta a reflexionar sobre la naturaleza de los nuevos retos sanitarios regionales y mundiales, y sobre la efectividad de las respuestas que los organismos internacionales de salud están ofreciendo para contender con estos retos.

Bajo el término de "transferencia internacional de riesgos y oportunidades"se agrupan, además de la diseminación de enfermedades infecciosas, fenómenos tales como la exportación de estilos de vida dañinos, el comercio de sustancias nocivas -algunas legales, como el tabaco y el alcohol, y otras ilegales, como las drogas-, la movilidad transfronteriza de consumidores y proveedores de servicios de salud, y la diseminación de problemas de salud asociados a fenómenos ambientales globales.

Además de adaptarse a estos y otros retos, los organismos internacionales deben enfrentar la diversificación y multiplicación de actores en el mundo de la salud internacional, que ahora incluye a las instituciones académicas, las organizaciones filantrópicas, las organizaciones no gubernamentales, el sector privado y los bancos de desarrollo. Estos últimos, por cierto, se han constituido, en un periodo de sólo 10 años, en los principales financiadores de las actividades de salud en el mundo en desarrollo.

Las instituciones multilaterales deben, asimismo, atendiendo a los procesos de democratización que se están dando en todo el mundo, promover una mayor participación de los Estados miembros en el diseño, implantación y evaluación de sus iniciativas, y establecer mecanismos de gobierno que garanticen la transparencia y la rendición de cuentas.

Los cambios recientes en las direcciones de la Organización Panamericana de la Salud (OPS) y de la Organización Mundial de la Salud (OMS) seguramente facilitarán estos procesos de reflexión. De hecho, los cambios en las direcciones de estas organizaciones fueron antecedidos por discusiones -algunas promovidas por instituciones filantrópicas como la Fundación Rockefeller, otras por publicaciones académicas como BMJ y Lancet, y otras más por organizaciones no gubernamentales como Medecins Sans Frontieres- en las que se enfatizó la necesidad de discutir la naturaleza de los nuevos retos, las funciones esenciales que en este nuevo entorno deberían jugar los organismos multilaterales de salud y las estructuras organizativas idóneas para el desempeño de sus posibles nuevas funciones. El propio Secretario General de la Organización de las Naciones Unidas, Kofi Annan, hace unos días afirmó: "los Estados Miembros deben examinar detenidamente la actual arquitectura de las instituciones internacionales y preguntarse si están realmente adecuadas a las tareas que nos esperan".*

* Piquer I. Kofi Annan abre el debate sobre las reformas de la ONU después del fracaso del conflicto iraquí. El País 2003;septiembre 10:3. 
Salud Pública de México no quiere quedarse al margen de estas discusiones y por esta razón pública en este número el discurso de toma de posesión del nuevo Director General de la OMS, doctor JW Lee, y una entrevista con él. En números futuros esperamos dar a conocer también las propuestas de la nueva admi- nistración de la OPS. Estos y otros documentos se publicarán con el objetivo de ayudar a incorporar a la comunidad de sanitaristas de América Latina a este importante debate.

Octavio Gómez Dantés*

* Dirección General de Evaluación del Desempeño, Secretaría de Salud, México. 